\title{
IMPORTANCE OF THE TRANSLATION QUALITY OF MULTILINGUAL MENUS IN HOSPITALITY INDUSTRY
}

\author{
Alenka Suljić Petrc ${ }^{13}$ \\ Ivana Edmonds ${ }^{14}$
}

\begin{abstract}
Introduction: Direct contact with a guest is realized verbally for which tourist workers' knowledge of foreign languages is necessary. Apart from the verbal contact with employees, menus in hospitability facilities still serve the purpose of a business card that with its design, print, size, food and facility information, and multilingualism is a symbol of restaurant's identity and theme. By analyzing the available research, direct and indirect consequences of unprofessional translations are apparent, resulting in the incomprehensible text of a restaurant offer. Objective: In this paper the author will make a review of available literature with the aim to investigate in systematical way the existent researches dealing with the issues of quality menu translations as well as the most common present translation strategies for translating such professional texts. Material and methods: A range of methods is available for synthesizing diverse forms of evidence. These include thematic analysis, grounded theory and qualitative comparative analysis. Methods vary in their strengths and weaknesses, ability to deal with qualitative and quantitative forms of evidence, and type of question for which they are most suitable. Results and conclusion: After a systematic analysis of the previously mentioned issues through available literature, the authors' conclusion is that the menu status should be determined as a text for special purpose dedicated to the specific target group of guests - tourists. The menu language needs to be adjusted in a clear and simple way keeping the characteristics and style of food in informative function on a foreign language.
\end{abstract}

Keywords: menu, translation, guest, tourist destination, restaurant

\section{INTRODUCTION}

Global restaurant industry has been increasing continuously, as well as its competition. According to this, it is customer satisfaction that is essential in forming customers' loyalty, and consequently, in satisfying business performance (Khodr, Assaker, Assaf, Hallak,2016).A direct contact with a guest is realized verbally due to which tourist workers' knowledge of foreign languages is necessary. They, through the direct contact with the guest, have the ability to leave positive impression, which will allow the same guest to return to the destination or to that hospitability facility.

\footnotetext{
${ }^{13}$ Business languages, Department of foreign languages, Faculty for tourism and hospitality management, University of Rijeka, alenkasp@fthm.hr

${ }^{14}$ Language Stars, School of languages, ivana.edmonds@hotmail.com
} 
Verbal communication between guests is sometimes (if not often!) replaced by the written text presented in the restaurant menus, wine cards and other written materials present in majority of hospitality facilities. The Oxford English Dictionary offers a variety of menu definitions, but the one that describes a menu as a list of dishes available at a restaurant demonstrates its informative and basic character in ordering food and guests' expectations. Apart from it being the verbal contact with employees, menus in hospitability facilities still serve the purpose of a business card that with its design, print, size, food and facility information, and multilingualism is a symbol of restaurant's identity and theme. The communication in foreign languages between employees and guests should be continuation of the previously acquired information read in the menu. By analyzing the available research, direct and indirect consequences of unprofessional translations are apparent, resulting in the incomprehensible text of a restaurant offer. The unclear translation causes the wrong choice of guests what, in most cases, causes the guest not to return.

The main objectives of this paper is to investigate the existent researches about the importance of restaurant menu translation quality and to explore the presence of translation strategies in restaurant menus. This review tends to define the role of menus as a sales tools which can effectively influence on restaurant's image and profit.

\section{THE RESEARCH BACKGROUND}

\section{Importance of quality / professional menu translation}

While starting to explore the importance of translation quality of multinlingual restaurant menus, the authors faced the astonishing fact of marginalized position of the above mentioned topic. There is lack of awareness that quality translation of restaurant menus is important to present a hospitality facility.

Adrian Fuentes-Luque (2016, p.177-188) highlights that the cuisine and restaurants are the powerful tools for cultural, social and tourist image-buidling. This is essential especially in major tourist destinations which are trying not to lose their image and reputation. In this way, some interesting traditions and dishes of the host county are presented to tourists and are considered to be one of the most visited attractions.

Furthermore, Fuentes-Luque states that quality tourism needs quality products and services. That is the starting point analysis for quality translated restaurant menusin the southern Spanish region of Andalusia. The main objective of this analysis was to reveal the main types of errors found in these types of texts. Over one hundred restaurant menus were presented in the paper and were classified through an error categorisation framework. One part of the methodology included even a questionnaire 
for professional menu translators.English as a lingua franca was taken in consideration in this study.

The main conclusions and recommendations of that study arethat menus should be considered as presentation cards of restaurants and destinations (Fuentes-Leque, 2016). The food items in restaurant menus need to be accurate and appropriate. This was concluded from the menus analayzed in Andalusia resulting in very unprofessional translations, which were mostly done by the freelance and in-house translators. A lot of hired translators admitted that restaurant owners and managers are rather reluctant in hiring professional translator services to translate the menus of their restaurants. Even if there are 27 translation agencies present in the entire region of Andalusia, only 4 of them were contacted for restaurant menu translations. This proves the lack of awareness of how much important is the accurate and quality translation of menus.On the other hand, the human translators are also rather replaced by Google Translator and that kind of automated translations, noticed Fuentes-Luque, is increasingly developing. As a consequence remains the incapability of quality food items translation and description of dish ingredients. To sum it up, it is necessary to consider menu translations as a specialised professional task which will be performed by trained, qualified translators.

Almost on the same path is the research of menu translations in restaurants in the Kvarner Region (Croatia) where the authors tried to define the role of menus and their quality translation as the tool of effective influence on restaurant's image and profit (Šuljić Petrc,Mikinac, Edmonds 2019, pp. 689-703). The aim of this research was to answer the question of how quality translated menus could help and contribute to better business and customer satisfaction. This research paper analyzed the most visited restaurants in one of the leading tourist regions in Croatia focusing on how translations in English language can provoke misunderstandings and lack of essential knowledge connected not only with scarse language background but also with the professional/culinary expertise.

While in the process of obtaining the menus and information about the menu translators, the authors had a direct contact with the restaurant owners, managers and even waiters and chefs. The majority of them confirmed the problem of incorrect translations which they discovered by the customers' remarks and observations. The reasons for it were mainly related to the fact that the translations of restaurant menus were not considered as an important part of an offer but just as something that was traditionally present in the restaurants. As a result, finding cheaper solutions such as hiringunprofessional translators, rather than professional and experienced ones, seems quite spread practice among the restaurant owners. On the other hand, the results of this research showed that even the menus translated by professional translators are not 
completely correct. There is no consistency in translations and very often, the translators would not explain well the local dishes leaving the guests wondering about their food choices.

Without doubt, a quality translated restaurant menu inevitably creates a bond with a tourist who wants to experience a different cuisine, unfamiliar flavors, but also on top of that, to exactly understand what he/she is eating( 2019, pp. 689-703).

Pouget (2000, pp.323-332)compares the menus that are translated by professional translators and those that are translated by inadequte translators in Spain. Her research included over thousand menus. There is one part of the translations from Spanish to English language made by the professional translators within a certain period of time. This period was followed by a period in which they were translated by inadequate translators.It just shows how the English language became more internationally used, and people felt safer while they were using it. It is because of this that the amount of professional translation was reduced believing that inadequate translations are good enough. The menu translation analysis in this research was mainly focused on trying to find translations that are insufficient for the complete understanding of a restaurant offer, lacking the additional description to better understand ingredients, meal preparation, and taste.

Quality menu translation implies functionality of translations of such texts, which is truly needed since the question is about texts that constitute the key element for further communication process between a client and employees. According to Li (2019) the only purpose of the translated menus is not just to be a communication tool used by customers and hosts, but also to facilitate processes in tourism and consumerism in general. Munoz (2011) confirms that an intercessory role of translation in tourism is shown as a very important factor in the tourism sector.

\section{Menu psychology}

Trostler and Gvion (2007, pp. 255-262)define restaurants as institutions which are oriented towards a client, while their menus represent a list of food, or the repertoire that serves to attract clientele. In fact, the purpose and goal of hospitality facility, especially in the tourist destinations, is to attract the potential customers and to create quality competition with other hospitlity facilities.

The menu design, its print quality and visual concept in general, motivated some researchers to investigate/understand menu psychology. Reynolds, Merritt and Pinckey (2005, pp. 1-99). This research concluded that each year restaurateurs spend 
great amount of time and resources on restaurant menus but it was impossible for the authors to evaluate the contribution at the bottom line. They confirmed that a menu is an integral part of any restaurant and noticed that its indispensable aspect of the business remains some kind of a mystery. The need of further scientific inquiry is necessary to clarify the importance of menu design and its influence on a restaurant's image and reputation.

Continuing on this track, Mc Call and Lynn (2008, pp. 439-445) deal with variety of suggestions on how restaurants should "manage" their menus. They examined in what way the menu description complexity can increase perceptions of item quality and expected price. In conclusion, they also noticed two different types of view by the academic researchers and practitioners. First one states that the menu is an important communicative tool and, exploring the evidences, the menus should be described in simple terms. Second one suggest that more complex and elaborate descriptions could lead to higher quality assessment of restaurant menus.

In the study led by McCall \& Lynn (2008), 160 students participated in a survey about food preferences and behaviour in the restaurant. They concluded that descriptive complexity and price information influence perception of quality, price expectations and the spending intentions. Descriptive complexity of the offered dishes in the restaurant menu should increase if the upper-item selection is to be presented. According to this, these dishes would be more chosen in comparison to those that are described in simpler way. McCall \& Lynn agree that the price is in direct connection with quality, which leads to conclusion that higher quality dishesare more expensive.

Moreover, Mills and Thomas (2008) claim that understanding of customers' expectations is viewed as an interpretation process by which customers make sense of the restaurant environment, which is an integral part for a restaurant's success. By analyzing the available research, direct and indirect consequences of the unprofessional translations are apparent, resulting in incomprehensible text of a restaurant offer.

\section{Menu translation strategies}

The complexity of restaurant menu translation is obvious and it requires the presence of theories and strategies that aim towards better understanding of the menu translation process. Menu contents affect the guest's reaction who makes a conclusion based on simple rules and personal decisions. These contents should be translated into multiple languages in such a way that they are just as appealing as the original to attract guests from different countries and different cultures.In this way, the guest would feel more comfortable reading about food in his/her own language, and the 
waiters would have a tool with which would be easier to communicate with their guests.

Foreignization and domestication, two cultural strategies in translation postulated by Venuti (1995) are used by many reserchers dealing with the problem of quality translation of restaurant menus. Domestication as a type of translation strategy uses, according to Venuti (1995), a transparent, fluent and invisible style in order to minimize the foreigness of the target text and lead the text to be familiar and recognizable. On the other hand, foreignization represents the strategy where a translator breaks target conventions by retaining something of the foreigness of the original. In this way, a dish may seem more authentic when read about and recognizable.

Ghafarian, Kafipour and Soori (2016) highlight two cultural strategies in translation postulated by Venuti (1995). These two strategies are also used by Amin Amir Debbaghian (2014) as a basis for different techniques of menu translation parallely revealing advantages and disadvantages of these strategies. Applying them to the translation of traditional Iranian dishes in English language, he concluded that the tourist-oriented approach is the most important.

Venuti'smodels, along with awareness of cultural obstacles that multilingual restaurant menus can represent, lead to conclusion that a menu should be recognized as a symbol of identity and a restaurant theme.

Exploring available literature about restaurant menu translating strategies the most commonly found are the following: Borrowing (strategy used when there is a lack of equivalence and the terms can be borrowed from other languages); Literal Translation (the strategy that preserves the term from the source language and it is difficult to translate it into the target language); Amplification (strategy when the translator adds some information or expression that are not present in the original text); Reduction (strategy that omits the terms considering them inappropriate or complicated for the target language); Translation by Cultural Substitution (this strategy is used by translators where the cultural substitution in translation is needed to better explain the meaning of food items).

The frequency of literal translation should be avoided by using techniques that will take into account the cultural diversity and diversity of guests, as well as the tourist destination in which they are located. In this way, it is necessary to overcome these differences to mutual satisfaction.

The name of the dish should correspond to what can be expected from the very taste of the dish. Various researches on this topic show that descriptive names improve sales 
because such dishes are considered more tasty, attractive and desirable. Sensory assessment of food can also be influenced by the name of the meal or even mentioning the ingredients of the dish. For example, Wansik, Ittersum Painter (2001) in their research claim that even just mentioning some of the ingredients or attributes of some dishes as "reduced fat" or "allowed by Atkins diet" contributes to either positive or negative reactions. In order for the guest to experience this, the language must be understandable. It plays a very important role in creating a link between the written words on the menu and the guest himself.

\section{METHODOLOGY AND MATERIAL}

In this paper a range of methods available for synthesizing diverse forms of evidence are used. These include thematic analysis, grounded theory and qualitative comparative analysis. The methods vary in their strengths and weaknesses, ability to deal with qualitative and quantitative forms of evidence, and type of question for which they are most suitable. The authors analyzed the current literature and based on that knowledge they identified the above-mentioned approaches included in this systematic review. The dates of texts reviewed range from 1995 to 2019 and they are mostly searched on Google Scholar, as well as the websites of some key organizations. Finally, the authors traced relevant documents from the references in the obtained texts.

The first step was to identify key texts that included already existing texts concerning the topic of restaurant menus and its importance in hospitality sector. Faced with the limitations of a small number of texts dealing with that topic, the focus should be widen to other problems regarding translations of restaurant menus.

This paper was a preliminary trial in the authors' research resulting in publishing of other paper dealing with the similar problematic and including the deeper analysis of menu translation while focusing on the translation strategies used in hospitality facilities in one popular tourist destination in Croatia.

\section{DISCUSSION, CONCLUSION AND CONTRIBUTION}

The conditions of doing business in hospitality are changing rapidly. The last decade has witnessed a substantial growth and rapid changes, globally, as well as domestically. Customer satisfaction has become a critical issue for the success of any business system, hence one of the key challenges in hospitality is how to satisfy and retain customers. In order for restaurants to grow and survive, they must find new ways of thinking, new ways of communication, which has led to various marketing researches, especially those related to customer satisfaction. Therefore, new ways of 
communication need to include intercultural component present on every level spoken (customer and employee dialogue) and written (restaurant's menu).

The fact is that a high quality of translations affects the customer's requirements and ensures that such translations are within the hospitality facilities' owners interests, as well as it introduces them professionally, taking into account the content of the translated dishes and its design.

The problem of having an adequate and correct translation of restaurant menus is wellknown amongst the researchers who are dealing with this topic. An inappropriate attitude towards the importance of correct menu translations can result in decreasing quality offer of a restaurant. The fact is that a menu represents a set of dishes which are served during the same meal but it has to be the aim of each hospitality facility to make/design/translate that menu in the way the guests would like. Choosing the right words accompanied with appropriate and appealing description asks for experience and expertise.Hiring professional translators and offering them adequate collaboration when translating specific food items on the menu, should be common practice of all restaurant owners and managers.

The main contribution of the paper is the analysis of the menu translations and present strategies for translation which influence the quality of intercultural communication, as well as the service quality and customer satisfaction. The fact is that most of the restaurants are successful because of the loyal and satisfied customer base. The available literature for deeper research on this topic is limited, but it represents the quality basis for further exploring the reasons of translation quality of multilingual menus in hospitality industry. 


\section{REFERENCES}

1. Al-Rushaidi, S. M. S., and Ali, H. I. H. (2017). Translating food menus from English into Arabic: linguistic and cultural dilemmas. AWEJ for Translation and Literary Studies, 1(1), 201-212.

2. Beldona, S., Buchanan, N., Miller, B.L. (2013). Exploring the promise of etablet restaurant menus. International Journal of Contemporary Hospitality Management, 26(3), 367-382. doi: 10.1108/IJCHM-01-2013-0039

3. Bowen, J. T. and Morris, A. J. (1995). Menu design: can menus sell. International Journal of Contemporary Hospitality Management, 7(4), 49.

4. Chiaro, D., Rossato, L. (2015). Food and translation, translation and food. The Translator, 21(3). 237-243, doi:10.1080/13556509,2015.1110934

5. Chłopicki, Władysław (2018) Translation of menus: Labour of Sisyphos, squaring the circle or marrying water and fire? Folklore (14060957) Vol. 71, p155-178. 24p.

6. Cho, H., Kinny, D., \& Lin, D. (2013). Parallel Prototyping for Multi-language Service Design: A Case Study on Introducing a Multilingual Tool into a Japanese Local Restaurant. 2013 International Conference on Culture and Computing. doi:10.1109/culturecomputing.2013.23

7. Cohen, E., Avieli, N. (2004). Food in Tourism: Attraction and Impediment. Annals of Tourism Research, 31(4). 755-778. doi:10.1016/j.annals.2004.02.003

8. Colina, Sonia. (2008). Translation Quality Evaluation: Empirical Evidence for a Functionalist Approach. The Translator 14 (1): 97-134.

9. Dabbaghian, A. (2014). Translation and Tourism: A Cross Cultural Communication and the Art of Translating Menus. Journal of Basic and Applied Scientific Research, 4(4), 11-19. Preuzeto s: https://www.textroad.com/pdf/JBASR/J.\%20Basic.\%20Appl.\%20Sci.\%20Res .\%204(4)11-19,\%202014.pdf (10.08.2018.)

10. Duran Munoz, I. (2011). Tourist Translations as a Mediation Tool: Misunderstandings and Difficulties. Cadernos de Tradução, 1(27), 29 - 49. doi: 10.5007/2175-7968

11. Fakih, K., Assaker, G., Assaf, A.G., Hallak, R. (2016). Does restaurant menu information affect customer attitudes and behavioral intentions? A crosssegment empirical analysis using PLS-SEM, International Journal of Hospitality Management, 57 (2016) 71-83

12. Fuentes-Leque, A. (2016). An approach to analysing the quality of menu translations in southern Spain restaurants. Journal of Multilingual ans Multicultural Development, $\quad 38(2), \quad$ 177-188. doi:10.1080/01434632.2016.1187154 
13. Gentzler, Edwin. (2001) Contemporary Translation Theories. Clevedon: Multilinual Matters.

14. Ghafarian, M., Kafipour, R., Soori, A. (2016). Domestication and Foreignisation Strategies in Restaurant Menu Translation. Pertanika Journals Social Sciences and Humanities, 24 (4), 1417-1429. Preuzeto s: https://www.researchgate.net/publication/311816390_Domestication_and_For eignisation_Strategies_in_Restaurant_Menu_Translation

15. Gleitman, L., \&Papafragou, A. (2005). Language and thought. In K.J. Holyoak, \& R. G. Morrison (Eds.). The Cambridge Handbook of Thinking and Reasoning, (pp. 633-661). New York: Cambridge University Press.

16. Hongyang, Bi (2017) The impact of using a foreign-language in restaurant menus on customers' attitude and behavioural intention. Master of International Hospitality Management, Auckland University of Technology.

17. Horvatić, A., Bačić, L. (2013). Nove tehnologije kao promotori turizma i gastronomske ponude Hrvatske. Preuzeto s https://hrcak.srce.hr/130307 (12.07.2018.)

18. Kalenjuk, B., Tešanović, D., Banjac, M. (2016.) Struktura i dizajn jelovnika u ugostiteljstvu Srbije kao značajnog prodajnog sredstva u turizmu. Turističko poslovanje, br. 18, str. 91-98. doi:10.5937/TurPos1618091K

19. Lessel, P., Bohmer, M., Kroner, A., Kruger, A. (2012). User Requirements and Design Guidelines for Digital Restaurant Menus. 7th Nordic Conference on Human-Computer Interaction: Making Sense Through Design, 524-533. doi:10.1145/2399016.2399096

20. Li, S. (2019). A corpus-based multimodal approach to the translation of restaurant menus. Perspectives, 27(1), 1-19.

21. McCall, M. and Lynn, A. (2008). The effects of restaurant menu item descriptions on perceptions of quality, price, and purchase intention. Journal of foodservice business research, 11(4), 439-445.

22. Mills, J. E., and Thomas, L. (2008). Assessing customer expectations of information provided on restaurant menus: A confirmatory factor analysis approach. Journal of Hospitality \& Tourism Research, 32(1), 62-88.

23. Mills, Juline E., Th omas, L. (2008). Assessing Customer Expectations of Information Provided On Restaurant Menus: A Confirmatory Factor Analysis Approach. Preuzeto s: https://doi.org/10.1177/1096348007309569

24. Munoz, I. D. (2011). Tourist translations as a mediation tool: misunderstandings and difficulties. Cadernos de tradução, 1(27), 29-49.

25. Ozdemir, B., and Caliskan, O. (2014). A review of literature on restaurant menus: Specifying the managerial issues. International Journal of gastronomy and food science, 2(1), 3-13. 
26. Pouget, C. F. (2000). Are Menu Translations Getting Worse?: Restaurant Menus in English in the Tarragona Area. Target. International Journal of Translation Studies, 12(2), 323-332.

27. Reiss, Katharina and Hans J. Vermeer. (1984-1996). Grundlegung einer allgemeinen Translationtheorie. Tubingen: Niemeyer.

28. Reynolds, D., Merritt, E. A., and Pinckney, S. (2005). Understanding menu psychology: An empirical investigation of menu design and consumer response. International Journal of Hospitality \& Tourism Administration, 6(1), 1-9.

29. Šuljić Petrc, A., Mikinac, K., Edmonds, I. (2019) Strategic approaches to menu translation analysis, ToSEE, Vol. 5, pp. 689-70

30. Trostler, N., and Gvion, L. (2007). Trends in restaurant menus: 19502000. Nutrition today, 42(6), 255-262.

31. Vorajaroensri, Panida. (2002). An Analysis of Translation Strategies Used in Thai Restaurant Menus. Master's Project, M.A. (English). Bangkok: Graduate School, Srinakharinwirot University. Advisor Committee: Assist. Prof. Dr. TipaThep-Ackrapong, dr. NitayaSuksaeresup and Mr. Brett Heagren.

32. Walters, C. G. (1978). Consumer Behavior: Theory and Practice, Homewood, Richard D. Irwin, In.

33. Wansink, B., Painter, J., \& Ittersum, K. V. (2001). Descriptive Menu Labels' Effect on Sales. Cornell Hotel and Restaurant Administration Quarterly, 42(6), 68-72. doi:10.1177/00108804014260 